\title{
Towards A Poetics of Narrative Brevity: Short Story, Microfiction, Flash Fiction
}

\author{
Dr. Spyros Kiosses \\ Democritus University of Thrace, Department of Greek Philology, University Campus, Komotini, Greece \\ *Corresponding Author: Dr. Spyros Kiosses, Democritus University of Thrace, Department of Greek \\ Philology, University Campus, Komotini, Greece
}

\begin{abstract}
The universal popularity of very short fiction writing and reading calls for immediate theoretical and critical attention as to the conditions (technological, cultural, media, publishing, etc.) that favor narrative brevity, to matters of terminology and typology within the broader field of microfiction, as well as to its poetics and aesthetics. Some of the questions raised and discussed in this paper include the function and impact of concise narration, in general, and microfiction, in particular, the relation between microfiction and the short story, and the distinctive characteristics of the (sub)genre of flash fiction, which, as claimed, is a narrative actualization of post-modern fragmentality, in an attempt of writers (and readers) to make sense of their world.
\end{abstract}

Keywords: narrative brevity, short story, microfiction, flash-fiction

\section{INTRODUCTION}

There is no need to invoke modern research in linguistics, communication studies, or literary theory and criticism in order to prove that the way in which we speak and write, within the frame of any textual genre, is the result of many factors. Undoubtedly crucial among them is the means of synthesis, transmission/publication, and reception of one'sutterance. It is also obvious that the new socio-cultural conditions and developments in technology have influenced the form, content, and function of literary communication, opening up the horizons for the emergence of various modes of electronic literature and of a modern digital poetics(Earhart, 2015;Hammond, 2016; Hayles, 2008;Hockey, 2000;Murray, 2018; O'Sullivan, 2019; Rettberg, 2019, Steiner, 2010).In the above context, certain literary genres are promoted, the form of older ones is revised, while the emergence of new ones is endorsed(Hayles, 2008: 5).Social media are thus interrelated with genre theory and making sense of everyday life (Lomborg, 2014).

One of the most popular genres in the newly formed conditions is microfiction, also known as minifiction, nanofiction, sudden fiction, flash fiction, quick fiction, smoke-long fiction, postcard fiction, short short story, very short story, etc. (Botha,2016; Holdefer, 2014). ${ }^{\mathrm{i}}$ Modern digital media seem to favor the small text narrative form, which suits the requirements of tablet and mobile screens, and also corresponds to the time available to the average reader's reading and retention time amidst a wide variety of texts and/or other attractive options (Al-Sharqi \& Abbasi, 2015; Levin, 2020). Indeed, the social networking, communication channels and electronic applications that emerged in the age of the internet (blogs, Facebook, Twitter, Instagram, YouTube, Wattpad, Drabble, etc.) are characterized by the ability to quickly record the experience, (re)transmit it to a wide audience, usually for free, and often receive feedback from it -which could lead, in turn, to the modification of the original text. In addition, text may be combined with various semiotic resources and representation modes, such as images, symbols, maps, sounds, music, videos and so on, resulting in an enriched reading experience and, more importantly, in semantic broadening of literacy and literature.

The afore-mentioned conditions favor immediacy or, at least, the impression of it; they promote the direct authorial reflexes on contemporary stimuli of the socio-political environment and the recording and commentary of current issues of social interest. In addition, due to the texts' informal, familiar or familiar-like style, there is a tendency for the use of the first narrative person, as a rule, and/or the 
internal point of view, techniques that are related to the confessional tone, the "externalization" of a subjective way of perceiving the world, as well as a simple, everyday style. Accordingly, the reader response is also direct. It takes the form of comments on the text, demonstration of their like or dislike, sharing, reading stats, etc., as well as the composition of new texts on the occasion of the existing; this feedback may potentially lead to the modification of the original texts, shifting essentially the author-reader dynamic and the communication circuit (Murray \& Squires, 2013).iii Thus, the contemporary media convergence leads to a participatory culture and a new "collective intelligence" (Jenkins, 2006). However, the immediacy and rapidness of recording the experience and the (supposedly) direct transmission of the impressions it creates may affect the quality of the produced texts, leading to a lack of critical distance from the creative reason and the wider subject. It can also bring about excessive attention to detail, exaggerated subjectivity and projection of the personal gaze, persistently ironic and/or "warlike" attitude, crude and sloppy expression, stylistic uniformity, etc. Yet, these "pitfalls" can be successfully avoided, as shown by influential writers, from Borges and Beckett to Ishiguro, Munro, Davis, and many others, who have tested their creative powers in condensed narratives, with exquisite results. The popularity of short pieces of writing is moreover linked to the fact that they lend themselves to study and practice on creative writing and literature courses, and have become the subject of multiple writing competitions on an international level.

The popularity of microfiction, which I will use below as a hypernym term for the very short fiction (cf. Botha, 2016: 202), ${ }^{\text {iv }}$ raises many research questions regarding not only its thematic and morphological characteristics, narrative techniques, etc., or, in a nutshell, its poetics, but also the implications it may have on the very notion of narrativity and the reading of narrative. In an attempt to provide a rough definition of microfiction and its narrative structure one could do worse than compare it with the short story, its closest relative, as it seems. The short story is a piece of literary prose read "atone sitting", according to the well-known formulation of Edgar Allan Poe in his essay "The Philosophy of Composition" (1846). ${ }^{\mathrm{V}}$ The issue of length, however, is not so much important in itself, but is connected to other matters, such as the impression the text makes on the reader. As Poe claims in the aforementioned essay, "if any literary work is too long to be read at one sitting, we must be content to dispense with the immensely important effect derivable from unity of impression - for, if two sittings be required, the affairs of the world interfere, and every thing like totality is at once destroyed" (Poe\&Kennedy,2006: 545).Therefore, smaller texts foster a sense of "unity" or "totality" of the literary experience as an important effect on their recipient.

Poe had expressed similar views a few years earlier. In particular, in a critical note to the work of Nathaniel Hawthorne Twice-Told Tales, published in Graham's Magazine in May 1842, ${ }^{\mathrm{vi}}$ he argues that short prose narrative emerges as the most important field of practice for the highest writing talent in prose. In contrast to the novels and their large extent, Poe explains, the "brief tales" are read "at one sitting" (half an hour to two hours), a time period which gives the reader the impression of totality and unity. Thus, the author of these stories can fully realize his intention, whatever it is:"During the hour of perusal the soul of the reader is at the writer's control. There are no external or extrinsic influences - resulting from weariness or interruption" (Poe\&Kennedy, 2006: 533).

Following Poe, Brander Matthews argues that "the difference between a Novel and a Novelet is one of length only: a Novelet is a brief Novel. But the difference between a Novel and a Short-story is a difference of kind. A true Short-story is something other and something more than a mere story which is short. A true Short-story differs from the Novel chiefly in its essential unity of impression. [...] A Short-story deals with a single character, a single event, a single emotion, or the series of emotions called forth by a single situation" (Matthews, 1901: 15-16). As a result, "the Short-story is the single effect, complete and self-contained, while the Novel is of necessity broken into a series of episodes" (Matthews, 1901: 15-16).

Modern short story theory and criticism corroborates, along general lines, such observations. Obviously, there is a significant multiplicity of short story writing, which underwent substantial modifications, in terms of subject matter, narrative techniques, form, emphasis (e.g. in plot or psychology/climate), targeting, etc., from the time of its first appearance until today, especially under the influence of modernism and postmodernism (see Hanson, 1985, 1989; Head, 1992, 2006; Hunter, 2007; Patea, 2012). A core feature of the short story is that it gives the reader the illusion that they 
understand the totality before they have perceived the parts (May, 2011). Due to its limited scope and the possibility of a single and uninterrupted reception, the reader may approach it as a unified aesthetic whole. Moreover, the emphasis in short stories lays, as a rule, on the action of fewer characters, even one, in a limited number of events, which are characteristic of the central character and/or crucial for their sketching. Character sketching is rough, there is one line of plot, linear structure, space and time unity (or at least limited spatio-temporal variety), parts of the story are silenced or summarized (narrative ellipsis or synopsis), repetitions, rambling and descriptive details are avoided, while there is often a surprise ending. Brevity in length is associated, as a rule, with stylistic density, high formalization, implication, narrative economy, tight and coherent action, as well as the use of "poetic modes", such as metaphor, metonymy, connotation, symbolism, and lyricism. ${ }^{\text {vii }}$

May (2011) adopts Benjamin's view (Benjamin, 1970) that the compact form of the short story, unlike the novel, is associated with the avoidance of psychological analysis, detailed rational explanation or "information". From its very beginning, thus, the genre of the short story was associated with the unusual, the unexpected, the atypical, the unfamiliar, the mysterious, as well as with an increased sense of intensity in the reading experience. What the narrative focuses on are the basic mysteries of human experience, which can be narrated, but not explained in logical terms, while suggesting ways of handling matters that we cannot rationally understand. At the same time, in the context of the limited plot, in space and time, a complete action cannot not be depicted, nor can complex causal connections, motives, etc. be presented in detail; on the contrary, only parts of reality are reconstructed, that constitute occasions for introspection on a character's part. These short periods of their life are riddled with intense and meaningful experience that leads to the acquisition of some form of hetero- and/or self-knowledge. As a consequence, the condensed form of the narrative requires the attribution of wider significance to simple objects and facts: the special becomes universal, the detail acquires a metaphorical or symbolic meaning. ${ }^{\text {viii }}$

In the above context, and despite the great formal and thematic heterogeneity of the short story, which makes the formulation of a comprehensive and unified theory of the short story -as of any other genre, for that matter- a strenuous effort (May, 1976; May, 1994), various attempts have been made to identify the basic elements of its structure and organization (e.g. Bonheim, 1982; Friedman, 1988; McCabe \& Bliss, 2003; Wong \& Lim, 2014). There are usually three main parts detected, which correspond to the beginning, middle and end of the linear development of the story: (a) orientation, where elements concerning the spacio temporal setting, the characters and the fictional events are introduced, (b) complicating action, where there is some kind of crisis or problem for the characters and their action,(c) resolution, where the crisis or problem is solved, dealt with or, conversely, brings some negative results to the characters. Within these sections there may be distinguished various rhetorical Moves, i.e. smaller parts of the text, with specific formal and thematic characteristics, which are oriented to specific communication objectives, and perform a special function within the part of the text to which they belong. ${ }^{\mathrm{ix}}$

In the continuum of the morphological extent of prose works, microfiction (i.e. fictional narrative texts, typeset like prose, of less than $1.500-2.000$ words) may logically be considered to hold the ultimate end of verbal and semantic concentration. In fact, one could further argue that the smaller extent of microfiction is inversely proportional to the semantic concentration, the verbal accuracy, the intensity of the reading experience, the use of predominantly "poetic" modes, lyricism, symbolism, tone, rhythm, etc., elements that were already considered generic features of the short story. Even though the length of microfiction may not allow for the structuring and development of (all of the) distinctive parts, i.e. orientation, complicating action, resolution, or Moves, as is the usually the case with the short story, the reader, using their empathetic and hermeneutic capacities and reading experience, may fill in the gaps and complete the "whole" narrative picture. In other words, microfiction strips the narrative process to the nude and balances this reduction by giving the reader the opportunity to co-author the text. Narrativity thus emerges not only as a transmission of real, imagined or possible worlds by the conventional narrative techniques (plot, characters, time, place, etc.) - as is the case with the novel and, as a rule, with the short story, but also as the possibility of constructing such worlds with the active participation of the reader, by providing them with the least possible building materials, schemes, and resources. The very short story promotes the aesthetics of narrative minimalism. ${ }^{\mathrm{x}}$ 
However, is this really the case with all texts of microfiction? Could brevity, in some cases, render the text narratively ineffective, being thus, in Poe's words, "undue", that is, not able to provide a certain degree of reading duration which is "absolutely requisite for the production of any effect at all" (Poe \&Kennedy, 2006: 533, 546)?In Aristotelian terms, can texts that seem "exceedingly small" be aesthetically beautiful? Moreover, does all microfiction attain, or wish to achieve, that sense of "unity" or "totality" connected with the short story?

It is self-evident that the answers to such questions require a thorough examination of an adequate amount of microfiction writings. ${ }^{x i}$ However, it seems plausible that some sort of differentiation is in order within the broader area of microfiction. Although some texts seem, in essence, to be short stories that are very short, telling a more or less concrete story, not all microfiction can be subsumed under the same category of poetics and satisfactorily be characterized using identical aesthetic criteria as that of the short story. In other words, one may detect in the multiplicity of microfiction texts which emerged in the second half of the $20^{\text {th }}$ century onwards not only differences in theme, technique, structure, tone, style, etc., but also differences in the overall philosophical and artistic conception. Indeed, it might be the case that a considerable amount of microfiction comprises not just short stories that take up very little space, but also texts of a different poetics altogether. ${ }^{\text {xii }}$ Some of those texts, of very short length, even down to a hundred words or less, which we might designate as flash fiction(proper), are not merely mini short stories -in the same way as the short story cannot be considered a miniature of the novel. ${ }^{\text {xiii }}$ They seem to constitute, rather, a distinctive literary subgenre, despite the multiplicity of their variant manifestations, contingent on the diverse socio-cultural environments (European, North and South American, Asian, etc.), historical circumstances, and literary modes (classical, modern, post-modern, realism, symbolism, magical realism, fantasy, metafiction, etc.) in which they are cultivated. It is a subgenre that shares common elements with the short story(or can even be considered a phase in its evolution), but yet has its own distinctive patterns. As such, flash fiction texts deserve individual critical research that may lead to the identification of specific qualitative criteria, in order for us to arrive at any kind of theoretical formulation as to its generic conventions. Such criteria could then be used to differentiate between narrative texts which share brevity as a common feature: some constitute mini/nano/very/short short stories (more closely akin to the poetics of the short story), some belong to the subcategory of flash fiction, and some are potentially of a hybrid or borderline form. ${ }^{\text {iv }}$ In this light, we could offer a few remarks, which might contribute to the formulation of an idiosyncratic theoretical paradigm of flash fiction, as opposed to the very short story.

In a 1925 essay on O. Henry (1925), Boris Ejxenbaum claims that although in the novel the culmination of the main line of action must come somewhere before the ending, "the short story, on the contrary, gravitates expressly toward maximal unexpectedness of a finale concentrating around itself all that has preceded. In the novel there must be a descent of some kind after the culmination point, whereas it is most natural for a story to come to a peak and stay there. The novel is a long walk through various localities with a peaceful return trip assumed; the short story -a climb up a mountain the aim of which is a view from on high." (Ejxenbaum, 1968: 4).If we wish to expand on Ejxenbaum's metaphor, we can compare the flash fiction with the direct transfer of the reader to the top of a mountain -or perhaps just one or two steps before its peak. Its reader is abruptly placed on a hill or a mountain, from where they may observe areas that they could not have seen from another point, but also familiar places, observed, all of a sudden, from a new, prominent position. The reader has not experienced the "ascent", as usually happens when reading the short story, or even the very short story. They have not been prepared in any way for the moment of surprise, revelation, subtle empathy, perception or insight associated with the climax which the short story processes, albeit briefly and concisely. Instead, the reader of the flash fiction is set directly at this peak moment, puzzled as to the particulars of this narrative transposition; yet there they are, left to enjoy the view or be jolted by it.As if, sitting until then in the dark, a flash of lightning briefly illuminates for the reader the scenery, like the sudden, shocking, intrusive and abrupt light of flash photography (Flint, 2017).And after this epiphany-like reading exposure, afterimages continue to float for quite some time before the reader's eyes. Indeed, it is these afterimages that might be considered the sub-genre's main purpose of being: how the reader attempts to apprehend and interpret its meaning, embracing it in their (self) consciousness. 
Flash fiction, that is, in contrast to the short story and, to a certain extent, the very short story, does not and cannot aim at representing or constructing complete aspects of a fictional world, even with the reader's active participation. It rather(re) creates a fragment of such a world, consisting, so to speak, a screenshot or an inter-ruption of it. In fact, one could persuasively argue that, if the (very) short story aims at promoting some sense of totality, or at least an illusion of it, by projecting a more or less coherent picture of the/a world, a distinct feature of flash fiction is that it points out, instead, the impression of fragmentation, rupture and indeterminacy of identity and experience, of their perception and narrative (re)presentation. There is no concern to depict, or allude to, a broader picture. It projects a random, disconnected sense of life, thematically as much as by the narrative means it deploys: no emphasis is given to the details of the scene, to the specifics of the setting, or the depiction of wellrounded characters; no sense of completeness of plot or even any kind of structured narrative progression is promoted. On the contrary, the reader's attention is drawn to a distinct episode, incident, or instant in medias res, with an abrupt beginning and ending; to a character's single action, thought or decision; to a sudden and unexpected revelation or reversal in the character's and/or reader's understanding of things. ${ }^{\mathrm{x}}$ Moreover, it is not the specific situation, the characters involved in it and their implied background (psychological, ideological, chronological, etc.) that matter, but rather the momentary situational dynamics and the nuclear energy unleashed by its narration. ${ }^{\text {xvi }}$ The reader may, of course, fill in elements of space, time, setting, etc. by inference, make assumptions about characters and "backstories", and attempt to reconstitute some sense of a fictional world and its meaning. If in the (very) short story the reader is involved in constructing mentally a story through the given plot elements, in the flash fiction they may try to construct a plot through the given pieces of information (Van Acht, 2014: 35-36). However, this is unnecessary for the operation and the effect of flash fiction, if not vain at all. For, the feeling of incompleteness, of loss, of "darkness" in the surrounding narrative world heightens, in contrast, the light cast on the narrative kernel and its polysemy. ${ }^{\text {xvii }}$

Flash fiction, as described above, does not claim to be an ekphrasis, however sketchy, of some aspect of the world outside or within. Instead, what matters seems to be that the reader glimpses a signifant moment, which is apocalyptic (or ana-calyptic) of the characters', and perhaps their own, ever changing surroundings and inner world; or which may bring out, on the contrary, their inexplicability. They savor that intense moment, immersing themselves in a compressed narrative stock which is perceived in one glance, read slowly like a poem (Shapard, 2012: 49), even if with a (bated) breath, and it is persistent in its emotional and intellectual impact on the reader. Yet, all they are given textually is nothing more than a fragment. A fragment, what is more, which is not really a part of any one "whole" (or is not composed itself of parts; cf. Aristotle, Poetics VII. 38-39), but is axiomatically incomplete. Flash fiction instantiates narratively, in this sense, the notion of fragmentality, in the light of which the fragment is considered as "the state of being of becoming (hence neither a 'state' nor a 'being')" (Mellamphy, 1998: 85). ${ }^{\text {xviii }}$ Hence, only an approach that appreciates flash fiction as an artefact in a "state of being of becoming", as an intentional literary actualization of post-modern fragmentality, can do full justice to its function and poetics. In this respect, flash fiction is akin to the aesthetics of incompleteness or non-finito in sculpture and painting (Gilbert,2003; Rothstein, 1976).

\section{CONCLUSION}

To sum up, the very conditions in which the genre of microfiction is formed and cultivated are also closely connected to the modification and/or expansion of the notions of narrativity, literariness, and textuality. Literature is gradually seen and deployed as a means of enmeshment in an active procedure involving an on-going creation and reception of a web of texts - the roles of creator and receiver being often alternate, rather than as a fixed, pre-crafted "product" by a literary genius, which a more or less pathetic reader is meant to consume at a later stage. Literariness is thus regarded as an act(ion), within a broader communication process, comprising not only ready-made texts, but also "texts-inthe-making" and events "created, actualized and activated as performed and received. The literary 'product' can therefore be more or less tangible or intangible, more or less interactive or noninteractive, more or less fluid or nonfluid. It can employ one or multiple semiotic resources; it can be long lasting or ephemeral - its life span coinciding with its reception time" (Kiosses, 2019: 24).

Digital technology, thus, has influenced all factors of verbal communication, according to Jakobson's model: a constantly increasing number of people can become addressers, composers and publishers of 
text, achieving the possibility of immediate publication in modern electronic channels, without critical intervention of publishers or other intermediaries as "gatekeepers". ${ }^{\text {ix }}$ Accordingly, more people become potential addressees: they can receive texts directly, easily, and inexpensively, in a variety of places, times and circumstances. But more importantly, a new, dynamic concept of textual representation emerges, which is not limited to conventional water-tight, stable, hermetic and definitive print forms, but rather to modern flexible, fluid, temporary, and changeable Designs and Re-Designs of meaning (Cope \& Kalantzis, 2009: 175-178), reflecting a similar instantaneous, subjective relationship of the authors to their surrounding world, in a continuous and dynamic search for meaning. Social media and the internet, in general, are connected with the "destabilization" of the text, while rendering genre a dynamic and unstable notion. ${ }^{\mathrm{xx}}$ They offer a variety of delivery channels and media platforms for the composition, publication, negotiation, marketing, and promotion of the new digital texts and hypertexts, which are not confined by the limitations of traditional editorial and publishing practices of the past. Fiction authors now have to consider the technological changes including market sensing and digital self-promotion- that affect the means in which they reach their audiences (Flahive, 2017; Kinberg, 2014; Ramdarshan Bold, 2018). This might account for the fact that, although there are still many examples of microfiction collections written to be published in book form (or texts composed in/for other media and then published as a book), the usual individual or collective publication practice for microfiction is gradually connected to electronic means (eg. blogs, online newspapers, webzines/e-zines, etc.) rather than the "canonical" book format and its conventional claim of authority.

This, in fact, corroborates what seems to be the form's "chief cultural appeal: its democratizing and globalizing power" (Fuss, 2019: 408). Texts of microfiction, and especially of flash fiction, by exploiting the power of digital media, provide one with the ability to appreciate the beauty of the "small picture" in otherwise imperceptible moments of time. They have emerged as apt means for constructing micro-meanings, sometimes incomplete, yet illuminating, in authors' and readers' attempt to comprehend the self and the world they inhabit; even if it is a protean, imperfect, fragmentary and utterly unknowable self and world that one writes and reads about.

\section{REFERENCES}

Abbasi, I. S., \&L. Al-Sharqi (2016). Merging of the Short-Story Genres. Studies in Literature and Language, vol. 13 , no. 2, 1-6.

Abella, R. (2017).Iridescent Insects: Flash Fiction in the United States. Microtextualidades: Revista Internacional de microrrelato y minificción, vol. 1, 1-12.

Al-Sharqi, L., \&I.S. Abbasi (2015). Flash Fiction: A Unique Writer-Reader Partnership. Studies in Literature and Language, vol. 11, no. 1,52-56.

Batchelor, K. (2012). In a flash: The digital age's influence over literacy.In B. Batchelor (Ed.). Cult pop culture: From the fringe to the mainstream (pp. 77-88). Praeger.

Benjamin, W.(1970). The Storyteller: Reflections on the Works of Nikolai Leskov. In H. Arendt (Ed.).Illuminations(pp. 83-109). Translated byH. Zohn. Cape.

Bonheim, H. (1992).The Narrative Modes: Techniques of the Short Story. D.S. Brewer.

Botha, M. (2016). Microfiction. In A.-M. Einhaus (Ed.).The Cambridge Companion to the English Short Story (pp. 201-220).Cambridge University Press.

Cope, B.\& M. Kalantzis (2009). 'Multiliteracies': New Literacies, New Learning. Pedagogies: An International Journal, vol. 4, no. 3, 164-195.

Dufresne, J. (2018).Flash!: Writing the Very Short Story. Norton.

Earhart, A. E. (2015).Traces of the Old, Uses of the New: The Emergence of Digital Literary Studies. University of Michigan Press.

Ejxenbaum, B. M. (1968).O. Henry and the Theory of the Short Story. Translated by I. R. Titunik. Ann Arbor.

Evans, W. (1972). Poe's Revisions in His Reviews of Hawthorne's 'Twice-Told Tales.' The Papers of the Bibliographical Society of America, vol. 66, no. 4, 407-419.

Fishelov, D. (2019). The Poetics of Six-Word Stories. Narrative, vol. 27, no. 1, 30-46.

Flahive, G. (2017). Digital Self-Promotion for the Underdog Author: Creative Opportunities and Experimentation. Interscript, vol. 1, no. 2, 23-42.

Flint, K. (2017).Flash! Photography, Writing, and Surprising Illumination. Oxford University Press.

Friedman, N. (1988). What Makes a Short Story Short? In M. J. Hoffman \& P. D. Murphy (Eds).Essentials of the Theory of Fiction (pp. 153-169).Duke University Press. 
Fuss, D. (2019). Flash. New Literary History, vol. 50, no. 3, 405-410.

Gilbert, C. E. (2003). What Is Expressed in Michelangelo's 'Non-Finito.' Artibus Et Historiae, vol. 24, no. 48, 57-64.

Guimarães J. F. N. (2012).The Short-Short Story: A New Literary Genre. Strategic Book Publishing.

Hammond, A. (2016).Literature in the Digital Age: An Introduction. Cambridge University Press.

Hanson, C. (1985).Short Stories and Short Fictions 1880-1980. Macmillan.

Hanson, C. (1989).Re-Reading the Short Story. Macmillan.

Hayles, N. K. (2008).Electronic Literature: New Horizons for the Literary. University of Notre Dame.

Head, D. (1992).The Modernist Short Story. Cambridge University Press.

Head, D. (2016).The Cambridge History of the English Short Story. Cambridge University Press.

Hockey, S. M. (2000).Electronic Texts in the Humanities: Principles and Practice. Oxford University Press.

Holdefer, C. (2014). How Short Is Short? Journal of the Short Story in English [Online], 62.Retrieved from http://journals.openedition.org/jsse/1440. Accessed November 10, 2020.

Howitt-Dring, H. (2011). Making Micro Meanings: Reading and Writing Microfiction. Short Fiction in Theory and Practice, vol. 1, no. 1, 47-58.

Hunter, A. (2007).The Cambridge Introduction to the Short Story in English. Cambridge University Press.

Jenkins, H. (2006).Convergence Culture: Where Old and New Media Collide. New York University Press.

Kinberg, M. (2014). Market Sensing as a Tool for Fiction Authors. Journal of Marketing and Management, vol. 1, no. $1,45-57$.

Kiosses, S. (2019). Fostering creative literacy: theoretical conditions and pedagogy. European Journal of English Language, Linguistics and Literature, vol. 6, no. 2,18-25.

Levin, O. (2019). Techno-Poetics in Micro-Stories of the Digital Age: The Case of Alex Epstein. Digital Scholarship in the Humanities, vol. 35, no. 2, 342-352.

Lomborg, S. (2014).Social Media, Social Genres: Making Sense of the Ordinary. Routledge.

Matthews, B. (1901).The philosophy of the short-story. Longmans, Green and Co.

May, C. E. (1976) (Ed).Short Story Theories. Ohio University Press.

May, C. E. (1994) (Ed.). The New Short Story Theories. Ohio University Press.

May, C. E. (2011).Why Short Stories Are Essential and Why They Are Seldom Read. In P. Winther, et al. (Eds.) The art of brevity: Excursions in short fiction theory and analysis (pp. 14-25). University of South Carolina Press.

McCabe, A.\& L. S. Bliss (2003). Patterns of Narrative Discourse: A Multicultural, Life Span Approach. Allyn and Bacon.

Mellamphy, D. (1998). Fragmentality (thinking the fragment).Dalhousie French Studies, vol. 45,83-98.

Murray, P. R., \& C. Squires (2013). The Digital Publishing Communications Circuit. Book 2.0, vol. 3, no. 1, 323.

Murray, S. (2018).The Digital Literary Sphere: Reading, Writing, and Selling Books in the Internet Era. Johns Hopkins University Press.

Nelles, W. (2012). Microfiction: What Makes a Very Short Story Very Short? Narrative, vol. 20, no. 1, 87-104.

O'Sullivan, J. C. (2019).Towards a Digital Poetics: Electronic Literature \& Literary Games. Palgrave Macmillan.

Patea, V. (2012). The short story: an overview of the history and evolution of the genre. In V. Patea (Ed.).Short story theories: A twenty-first-century perspective(pp. 1-24).Rodopi.

Poe, E. A., \& G. R. Thompson (1984).Essays and Reviews. Literary Classics of the U.S.

Poe, E. A., \& J. G. Kennedy (2006).The Portable Edgar Allan Poe. Penguin Publishing Group.

Ramdarshan Bold, M. (2016). The Return of the Social Author. Convergence: The International Journal of Research into New Media Technologies, vol. 24, no. 2, 117-136.

Rettberg, S. (2019).Electronic Literature. Polity.

Rothstein, E. (1976). 'Ideal Presence' and the 'Non Finito' in Eighteenth-Century Aesthetic. Eighteenth-Century Studies, vol. 9, no. 3,307-332. 
Royle, N. (2014).Quick Fiction: Some Remarks on Writing Today.Mosaic, vol. 47, no. 1,23-39.

Shapard, R. (2012). The Remarkable Reinvention of Very Short Fiction. World Literature Today, vol. 86, no. 5, 46-49.

Shapard, R., \& James T. (1986) (Eds). Sudden Fiction: American Short-Short Stories. Gibbs Smith, Publisher.

Shapard, R., \& James T. (1989) (Eds.).Sudden fiction international: Sixty short-short stories. W. W. Norton.

Shapard, R., \& James T. (1996) (Eds.).Sudden Fiction (Continued): 60 New Short-Short Stories. W.W. Norton.

Shapard, R., \& James T. (2007) (Eds.).New Sudden Fiction: Short-Short Stories from America and Beyond. W.W. Norton.

Shapard, R., et al. (2010) (Eds.).Sudden Fiction Latino Short-Short Stories from the United States and Latin America. W.W. Norton.

Steiner, A. (2010). Personal Readings and Public Texts. Culture Unbound: Journal of Current Cultural Research, vol. 2, no. 4, 471-494.

Stern, J. (1996)(Ed.). Micro Fiction: An Anthology of Really Short Stories. W.W. Norton.

Swales, J. M. (2004).Research Genres: Explorations and Applications. Cambridge University Press.

Tarrayo, V. N. (2018). "Beauty in brevity: capturing the narrative structure of flash fiction by Filipino writers. $I$ manager's Journal on English Language Teaching, vol. 8, no. 2,36-56.

Thomas, J., \& R.Scotellaro (2018) (Eds.).New Micro: Exceptionally Short Fiction. W. W. Norton.

Thomas, J., \& R. Shapard (2006)(Eds.). Flash Fiction Forward: 80 Very Short Stories. W.W. Norton.

Thomas, J., et al. (1992) (Eds).Flash Fiction: 72 Very Short Stories. Norton.

Van Achter, E. (2012).Revising theory: Poe's legacy inshort story criticism. In V. Patea (Ed.).Short story theories: a twenty-first-century perspective (pp. 75-88).Rodopi.

Van Achter, E. (2014).Micro fiction and short fiction: surroundedby scaffolding on all sides. Forma Breve, vol. $11,29-39$.

Wong, V.-F., \& J. M.-H. Lim (2014). Linking Communicative Functions with Linguistic Resources in Short Stories: Implications of a Narrative Analysis for Second Language Writing Instruction. System, vol. 45, $147-162$.

Wright, F. A. (2012). The Short Story Just Got Shorter: Hemingway, Narrative, and the Six-Word Urban Legend. The Journal of Popular Culture, vol. 47, no. 2, 327-340.

Zavala, L. (2012). The boundaries of serial narrative. In V. Patea (Ed.).Short story theories: a twenty-firstcentury perspective (pp. 281-297). Rodopi.

'For popular anthologies of “stories in brief' see Fuss (2019: 408-409). Worth mentioning, among others, are: Shapard \& Thomas, 1986, 1989, 1996; Shapard et al., 2010; Thomas \& Scotellaro, 2018, Thomas \& Shapard, 2006. Prose and poeticliterary texts of brief length may, of course, be traced back in history in the oral or written tradition of many cultures (eg. fables, parables, anecdotes, etc. in Europe, haiku and haibun in Asia, etc.) (Howitt-Dring, 2011: 48-49, Stern, 1996: 15-19). These forms, although historical precedents of modern microfiction (or micro-literature), are connected to different conditions, artistic intention, and cultural function.

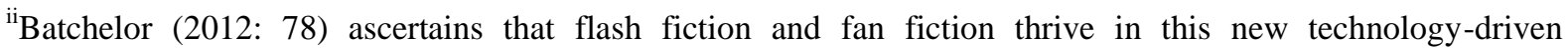
environment: "Interestingly, the fascination with fan and flash fiction is directly tied to the desire for brevity and instant gratification and the general obsession with celebrity and celebrity culture. In addition, people are writing more because they can use technology to bypass roadblocks created by the traditional publishing world. Writers in both genres can find an accessible audience on the Internet that wants to read these particular styles flash fiction for its brevity, combined with deep interpretation and feeling, and fan fiction for its link to celebrity and popular culture, particularly films and television”. Levin (2020), in her study of Alex Epstein's microstories, uses the term "techno-poetics" to describe the fusion of technology and poetics in the digital era. In Royle's (2014: 29) terms, "quick fiction has to be speed, nimble, agile, canny: it is necessarily responsive to and bound up with changes in technology, with what is quick, with what is happening in the world. But at the same time it is driven by a desire to veer away from all programming, from anything that is merely dutiful or expected". Yet, as he claims, it is not only, or not mostly, a question of speeding: "Countering the evanescence of so much 'cultural communication' today (the tweet, the text-message, and so on), quick fiction is more about that slowing down of perception that Viktor Shklovsky associated with the defamiliarizing power of art" (Royle, 2014: 29). Cf. Dufresne (2018, The intro).

iii In Lomborg's (28-29) words, "social media genres may be expected to exhibit more dynamic and unstable genre patterns, because a larger and more diverse number of producers and audiences are in direct dialogue, making feedback instantaneous, especially in synchronous, short-form genres such as micro-blogs or online 
chat. As a consequence of the direct feedback structure online, genres are likely to be organized in a more adhoc manner, as the horizons of expectations of the users as producers may be constantly challenged, reproduced, and adjusted through interaction with fellow users."

iv Apparently, there is not a general agreement on terminology or length limit of the genre. Nelles (2012), for example, adopts the term "microfiction" for texts up to 700 words, while for texts above that he uses the term "short story".

"On Poe's continuing influence on short story theory and criticism see van Achter (2012), who stresses "the failure of short story criticism toemancipate itself from the particular aesthetic paradigm set by Poe,Matthews and their successors" (van Achter, 2012: 82).

${ }^{\text {vi }}$ Poe wrote three critical notes on this work by Hawthorne: two in Graham's Magazine (a brief one in April and a more extensive one in May 1842) and one essay published in Godey's Magazine and Lady's Book in November 1847. His most important views on the short story are included in the note of May 1842. Some parts of this note are included as such in the text of 1847, some are modified, while in the later text there are several additions mainly in relation to the critical reception of Hawthorne's writings (see Evans, 1972). For Poe's views on short story and literature, more broadly, as set out in his reviews and essays, see Poe \&Thompson (1984).

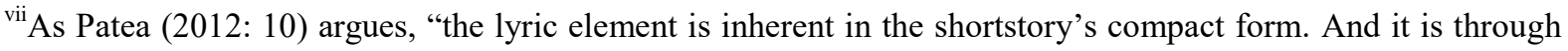
selection that the trivial detailbecomes charged with meaning. More stylized than the novel, theshort story tends to distort everyday reality more than long-formnarratives do and operates through intuition and lyric effects. In fact,lyricism is an inherent feature that derives from the tension andintensity of the short form and is present even in the most realisticshort stories".

viii As May concludes, "The very shortness of the short story, as well as the necessary artistic devices demanded by this shortness, force it to focus not the whole of experience, (whatever that is) in all its perceptual and conceptual categorization, but rather on a single experience lifted out of the everyday flow of human actuality and active striving, an experience that is lifted out precisely because it is not a slice of that reality, but rather a moment in which "reality" itself is challenged. The novel, by its very length, regardless of how many crisis moments it may present, still must in some way resolve them, cover them over, conceal them by the very bulk of its similitude to the ordinary flow of everyday experience. The short story, standing alone, with no life before it or after it, can receive no such comforting merging of the extraordinary with the ordinary" (May, 2011: 24).

${ }^{\text {ix }}$ Wong \& Lim (2014), based on the theory of Swales (2004), although they examine short stories in specific socio-cultural contexts and composed for a specific purpose, arrive at a format that could be more widely applied in the description of the short story, in general. According to this, the following Moves are identified: Move 1: Establishing a context; Move 2: Indicating a rising action; Move 3: Delineating the climax; Move 4: Indicating a falling action; Move 5: Providing a resolution.

xAccording to Guimarães (2012: 31), minifiction (the "short-short") mixes poetic condensation with the fictional narrative and the concise prose style of journalism.

${ }^{x i}$ Abella (2017: 4) correctly notes that,due to the hybrid and fluid nature of flash fiction, it defies definition and tabulation and is in great need of scholarly attention.

${ }^{x i i}$ As Zavalo (2012: 285) argues, "Throughout the twentieth century we find minifictions that can beread alternatively as prose poems, essays, chronicles, allegories orshort stories. Quite often, the same text is included in anthologiesdedicated to different genres, which reveals the insufficiency oftraditional generic norms to account for texts that cannot be classifiedwithin a specific canonical genre". This diversity, according to him, characterizes especially Spanish-American short fiction, in contrast to Anglo-American literature, where the conventional short-short story prevails. Flash fiction as a term originates in the '80ies (Thomas, et al.,1992). Ondiscussions about differences between flash fiction, sudden fiction, microfiction, prose poetry, vignette, etc. see, among others, Abbasi \& Al-Sharqi, 2016;Guimaraes, 2009; Howitt-Dring, 2011; Van Achter, 2014.

${ }^{x i i i}$ Quite popular is the six-word story, in the (alleged) manner of E. Hemingway ("For sale: baby shoes, never worn"). E.g. "Longed for him. Got him. Shit." (M. Atwood), "Defenestrated baby, methamphetamine, prison, rehab, relapse." (Jeffrey Eugenides), "In the end, everything simply began."(Ali Smith), etc. (see http://www. sixwordstories.net, Fishelov, 2019; Wright, 2012). As Van Achter (2014: 33) astutely observes,micro fictions (flash fiction, in our terms) are deliberately short: "Short stories are then naturally short, whereas micro fictions are manufactured short (being deliberately crafted to sub one hundred words, or even to a single sentence [...]".

${ }^{x i v}$ Cf. Shapard \& Thomas, 2007: 15: "Stories of only a page or two seemed to us different not only in length but in nature; they evoked a single moment, or an idea, whereas a five-page story, however experimental, was more akin to the traditional short story. Calling on the Wisdom of Solomon, we split the child (sudden fiction) [shortshort story] into two new children. The longer story became "new" sudden fiction, while the shorter became flash, named by James Thomas". In this vein, as far as length is concerned, the "new sudden fiction", more akin to the traditional short story , comprises texts of an average of 1.500 words, whereas the more radical form of "flash fiction" ranges between 750 and 250 words, or even fewer (Guimarães, 2012: 1-2, 35). Accordingly, 
microfiction texts that seem tocontain all of the components of short stories (setting, plot, characters, moves, steps, etc.), as supported in various studies (e.g. Al-Sharqi \& Abbasi, 2015; Tarrayo, 2018), belong in the category of very short stories, by our definition. Fuss (2019) studies "minis" as a type of flash, which "denotes stories that require turning one page, while 'minis' denote even shorter stories (of any brief length) that do not" (Fuss, 2019: 409). Botha (2016) studies particular forms (cycles, events, miniatures, fragments) in an attempt to reach a contemporary typology of microfiction.

${ }^{\mathrm{xv}}$ According to Batchelor, "the flash can be summed up as a three-point pattern; suck the reader into the middle of the story with action, swirl it with crisis, and end with an implied resolution. (It's a conflict, crisis, resolution connect-the-dot chart instead of the traditional five-point 'heart monitor' chart of the short story, which includes the rising action and climax" (Batchelor, 2012: 79).

${ }^{x v i}$ Nelles (2012) proposes a generic distinction between short stories and microstories (texts below 700 words) on the basis of action, character, setting, temporality, intertextuality, and closure. As he asserts, in most microstories the actions narrated are more palpable and extreme, character flattens out, giving its place to circumstance, the setting is virtually blank, duration is compressed, there are explicit or implicit intertextual references, and a relatively "closed", abrupt ending.

${ }^{\mathrm{xvii}}$ Van Achter compares microfiction to a recipe: "if micro fictions are, as previously imagined, all scaffolding and no building, all detail and no story, then they are not wholly dissimilar to a cooking recipe, and if you lose yourself too fully to the prose of the recipe, the meal itself will never manifest. The recipe ultimately fails because the reader fails to apply it" (Van Achter, 2014: 35).

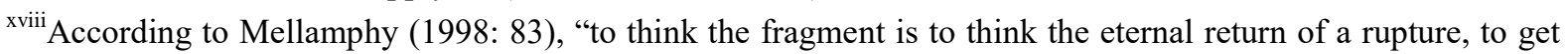
the drift of a rift, a fundamental fissure, a groundbreaking ground”. Mellamphy's essay proposes, thus, a series of principles or "demands", in an attempt to come to terms with the literary and/or philosophical fragment: " 1 . that the fragment breaks with the dialectic or part and whole; 2 . that the fragment, as something broken, has no form (or rather, informs -is informe, as Bataille would say); 3. that the fragment, informe, awaits $\mathrm{i}[\mathrm{t}] \mathrm{s}$ own formation and -what is more-calls for it or calls it forth; and 4. that the calling for form or formation is the very 'voice' of fragmentality, which is cut off as soon as its formation [is] achieved" (Mellamphy, 1998: 83).

${ }^{\mathrm{xix}}$ According to Ramdarshan Bold, Wattpad and other social writing platforms replace professional editing, designing, and marketing with crowd-sourced feedback and word-of-mouth social and viral marketing. Moreover, according to her research, "without the constraints of publishing gatekeepers, new trends, authors, and markets begin to emerge based on readers' tastes, participationwithin these reading communities, and personal relationships with the authorand the texts" (Ramdarshan Bold, 2016: 31, 32).

\section{AUTHOR'S BIOGRAPHY}

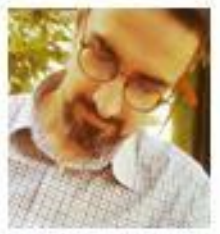

Dr Spyros Kiosses, teaches language, literature, and creative writing at the Department of Greek Philology, Democritus University of Thrace, Greece. He has a Master of Arts in Classics (University of Leeds, U.K.) and a Master of Science in Educational Research Methodology(Department of Educational Studies, University of Oxford, U.K). He completed his Ph.D. in Modern Greek Literature (Department of Primary Education, University of Thessaly). He is the author of books and papers on creative reading and writing, narratology, and the teaching of literature. His research interests include literary theory, education, and creative writing. e-mail: skiosses@helit.duth.gr

Citation: Dr. Spyros Kiosses. "Towards A Poetics of Narrative Brevity: Short Story, Microfiction, Flash Fiction" International Journal on Studies in English Language and Literature (IJSELL), vol 9, no.1, 2021, pp. 9-18. doi: https://doi.org/10.20431/2347-3134.0901002.

Copyright: (9) 2021 Authors. This is an open-access article distributed under the terms of the Creative Commons Attribution License, which permits unrestricted use, distribution, and reproduction in any medium, provided the original author and source are credited. 